\title{
The left atrial bacterial vegetative mass due to Corynebacterium striatum as a presentation of myxoma: a case report
}

\author{
Jun $\mathrm{Xu}^{1}$, Qing Yang ${ }^{2}$, Jun $\mathrm{Li}^{3}$ and Xia Zheng ${ }^{1 *}$
}

\begin{abstract}
Background: Corynebacterium striatum is a member of the non-diphtherial corynebacteria, which are ubiquitous in nature and generally colonize the skin and mucous membranes of humans. Rarely, it causes infective endocarditis (IE). We report a case of rare left atrial bacterial vegetative mass due to C. striatum masquerading as a myxoma identified through a tortuous diagnostic process, and present a brief review of the relevant literature.

Case presentation: We present a case of 63-year-old man who presented with progressively worsening dyspnea on exertion and lower leg edema, and was diagnosed with heart failure. Transesophageal echocardiography (TEE) revealed that the left atrium was filled with a $2.7 \mathrm{~cm} \times 2.6 \mathrm{~cm}$ mass. The patient, who had no signs of infection or related risk factors, was suspected of having a left atrial myxoma clinically. After excising the mass, the histopathology suggested thrombus with no myxocytes. Postoperatively, a fever appeared and C. striatum was isolated from the blood cultures. Although antibiotics were used, the symptoms of heart failure worsened gradually and echocardiography revealed valve vegetation. The patient underwent a second operation because of IE. Surprisingly, the mass was confirmed to be a bacterial vegetation due to C. striatum based on Gram staining at a 1000x magnification, although this was not noted on routine pathological examination of the two surgical specimens.
\end{abstract}

Conclusions: Physicians should be aware of Corynebacterium in blood cultures, which cannot simply be assumed to be a contaminant. A diagnosis of IE should be suspected, particularly in high-risk patients or those with an unexplained fever. Our patient had IE due to C. striatum with no risk factors. This case supports the diagnosis of IE using a combination of pathology and etiology.

Keywords: Infective endocarditis, Corynebacterium Striatum, Atrial myxoma, Bacterial vegetation, Case report

\section{Background}

Infective endocarditis (IE) is a lethal disease that has undergone major changes in both host and pathogens over the past 20 years [1]. The clinical presentation includes a fever, new or changing heart murmur, embolic phenomena [2], heart failure, dyspnea, splinter hemorrhages, Roth spots, and glomerulonephritis. However, atypical clinical presentations of IE are common in the elderly or immunocompromised patients [3]. Staphylococcus aureus is the most common cause of IE in most

\footnotetext{
* Correspondence: zxicu@zju.edu.cn

${ }^{1}$ Intensive Care Unit, The First Affiliated Hospital, College of Medicine,

Zhejiang University, 79 Qingchun Road, Hangzhou 310003, People's Republic of China

Full list of author information is available at the end of the article
}

of the industrialized world, whereas Corynebacterium striatum is a very rare cause.

Here, we present a patient with a left atrial bacterial vegetative mass due to $C$. striatum mimicking a myxoma, who was treated successfully with combined medical and surgical methods after a tortuous diagnostic process.

\section{Case presentation}

A 63-year-old man with a history of hypertension and atrial fibrillation presented with progressively worsening dyspnea on exertion and aggravated lower leg edema for 1 month without a fever, coughing, or sore throat. He had no history of surgery. The symptoms of heart failure markedly improved after a 2-week treatment with diuretics in a local hospital. However, echocardiography showed a mobile mass in the left atrium; therefore, the 
patient was transferred to our hospital for further treatment. On admission, his vital signs were blood pressure of $145 / 90 \mathrm{mmHg}$, atrial fibrillation with a ventricular rate of 81 beats per min, and a body temperature of $36.3{ }^{\circ} \mathrm{C}$. Laboratory tests showed a white blood cell (WBC) count of $3.8 \times 10^{3} / \mu \mathrm{L}$ (reference range $4.0-$ $10.0 \times 10^{3} / \mu \mathrm{L}$ ) with $44.7 \%$ neutrophils, and a serum hypersensitive C-reactive protein (hs-CRP) level of $8 \mathrm{mg} / \mathrm{L}$ (reference range $0.8-8 \mathrm{mg} / \mathrm{L}$ ). His urine and feces examinations were normal. Transthoracic echocardiography (TTE) revealed a $2.7 \mathrm{~cm} \times 2.6 \mathrm{~cm}$ left atrial mass that was suspected of being a myxoma (Fig. 1a). TEE also revealed a $2.7 \mathrm{~cm}$ left atrial mass attached by a thin stalk $(0.15 \mathrm{~cm})$ to the base of the atrial apex, swinging freely within the left atrial cavity (Fig. $1 \mathrm{~b}$ and Additional file 1). The patient was managed surgically. The mass was confirmed to originate from the atrial apex and appeared grossly myxoid and fragile. Surprisingly, however, the histopathology of the specimen showed no characteristic stellate mesenchymal cells to support the diagnosis of myxoma. Instead, it revealed a fibrinous exudate and chronic inflammation with a few mononuclear cells and a macrophage reaction (Fig. 2a). Therefore, the mass was considered to be a left atrial thrombus.

Despite the preventive use of cefuroxime sodium (1500 mg every $12 \mathrm{~h}$ ), his temperature increased to $39.5{ }^{\circ} \mathrm{C}$ on the fourth day. The WBC count increased to $9.5 \times 10[3] / \mu \mathrm{L}$ with $85.9 \%$ neutrophils and his hsCRP level rose to $183.9 \mathrm{mg} / \mathrm{L}$. Four sets of blood cultures were drawn. Urgent computed tomography (CT) of the chest showed bilateral pulmonary infiltrates with sputum culture positive for Acinetobacter baumannii. Consequently, cefoperazone, sulbactam, and fosfomycin were started. Nevertheless, his fever recurred for 2 weeks. The blood cultures yielded C. striatum (Fig. 2b) that was resistant to ceftriaxone, penicillin, meropenem, and clindamycin and sensitive to vancomycin. Instead of vancomycin, linezolid was chosen to treat the $C$. striatum bacteremia after considering the elevated creatinine level of $117 \mu \mathrm{mol} / \mathrm{L}$ (reference range 59-104 $\mu \mathrm{mol} / \mathrm{L}$ ). However, the symptoms of heart failure worsened gradually and echocardiography revealed valve excrescence and severe aortic insufficiency. Therefore, the patient underwent surgical management and treatment with $500 \mathrm{mg}$ daptomycin daily. A double valve replacement was performed. At surgery, a $1 \mathrm{~cm} \times 1 \mathrm{~cm}$ vegetation was seen at the left coronary cusp of the aortic valve, with perforation of the right coronary cusp of the aortic valve and moderate mitral regurgitation. The fever subsided rapidly and six sets of blood cultures obtained postoperatively were negative. Histological examination of the new vegetation indicated large numbers of Corynebacterium on Gram staining (Fig. 2c) and vegetation cultures confirmed that the bacterium was C. striatum. We also found the same Corynebacterium on the first surgical specimen using Gram and Wright's staining (Fig. 2e). We speculate that the left atrial mass was an occult bacterial embolus and large amounts of bacteria entered the blood stream and induced the valve damage after the first operation. Subsequently, the patient received a 4-week course of intravenous daptomycin and was switched

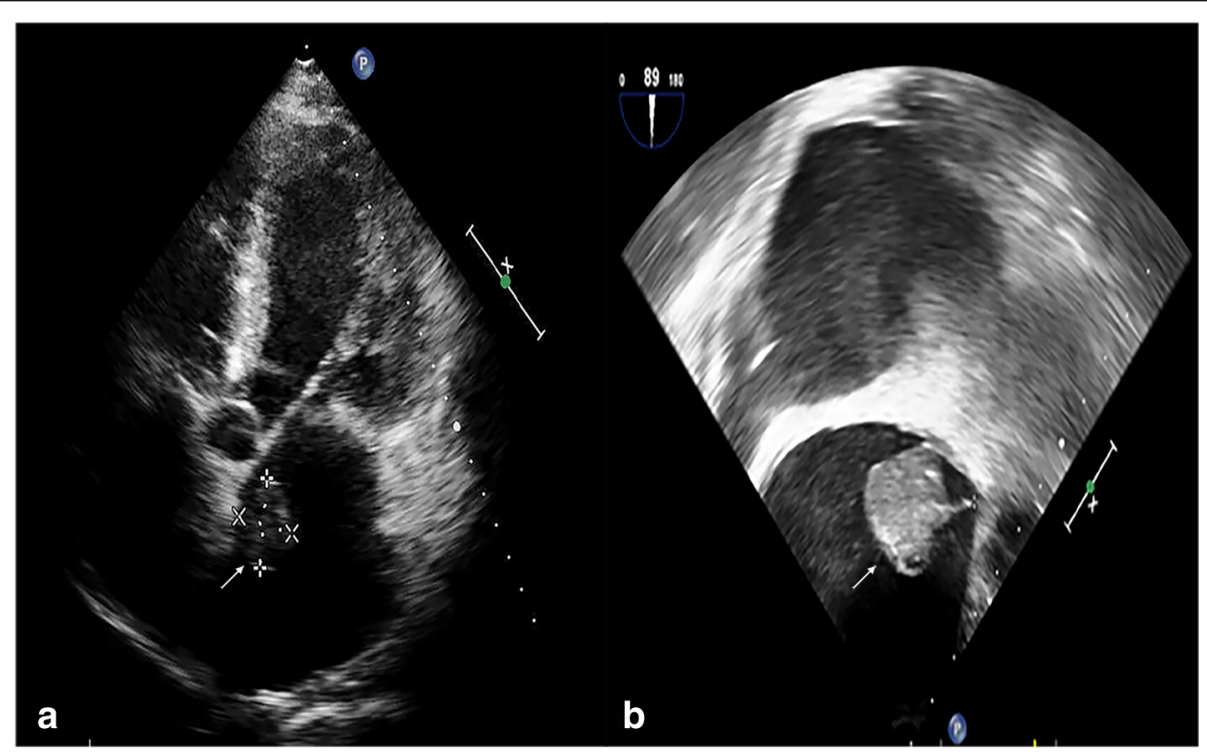

Fig. 1 a Transthoracic echocardiography and (b)transesophageal echocardiography showing a $2.7 \mathrm{~cm} \times 2.6 \mathrm{~cm}$ hypoechoic mass (arrow) attached by a thin stalk (measuring $0.15 \mathrm{~cm}$ in size) to the base of the atrial apex, freely swing within the left atrial cavity 


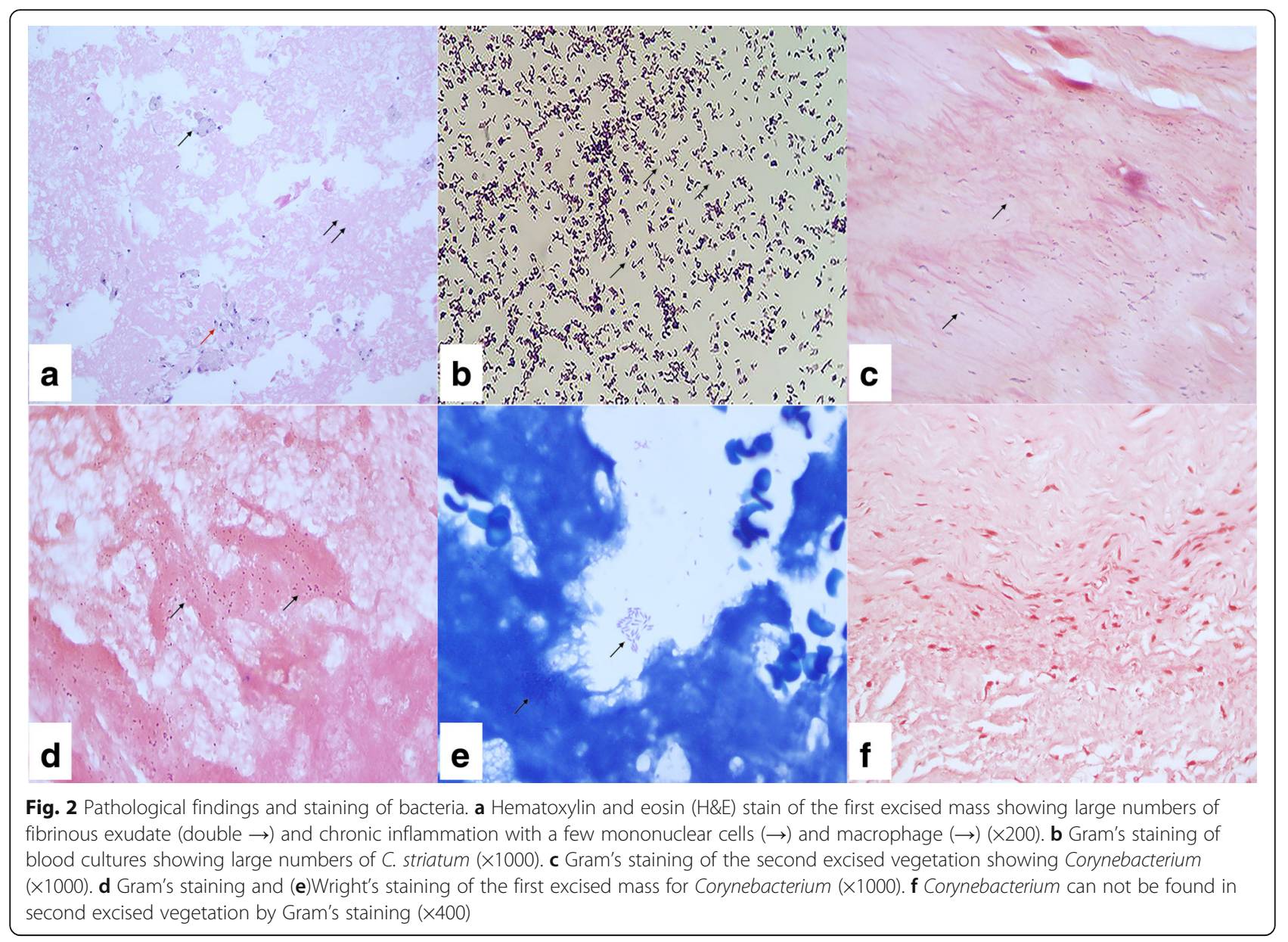

to oral linezolid for 3 weeks. The patient's general condition markedly improved and he was discharged from our hospital.

\section{Discussion}

IE is a potentially lethal disease with a low incidence (1.7-7.9 cases/100,000 inhabitants). C. striatum is a rare cause of IE, causing about $0.33 \%$ of all cases of IE [4]. As a member of the corynebacteria, C. striatum is a Grampositive, aerobic, non-sporulating bacillus that grows slowly in cultures and is distributed in the skin and mucous membranes of normal hosts and hospitalized patients. It is one of the more commonly isolated coryneform bacteria in the clinical microbiology laboratory and is usually considered a contaminant because of its low virulence. However, $C$. striatum can cause not only IE but also a variety of different infections such as pneumonia, empyema, peritonitis, arthritis, keratitis, intrauterine infections, wound infection, breast abscess, and osteomyelitis [5]. Risk factors for Corynebacterium endocarditis include pre-existing cardiac disease, a history of bacterial endocarditis, and the presence of prosthetic devices [6]. Rufael et al. [7] reported the first case of native valve endocarditis due to $C$. striatum, which required a combination of medical and surgical treatments [7]. Of the 24 cases of $C$. striatum endocarditis found in PubMed (Table 1) [6-30], most showed a predilection for heart valves. In our case, however, $C$. striatum colonized the left atrial apex masquerading as a left atrial myxoma instead of attaching to the heart valves. Looking back on our data, there were three main potential causes of misdiagnosis. First, the patient had no classic symptoms of IE on admission. Second, both TEE and the surgical findings supported the diagnosis of left atrial myxoma. Third, the initial histopathology was misleading.

The category "definite IE based on clinical criteria" involves with at least two major criteria, or one major criterion and three minor criteria, or five minor criteria. Major criteria include blood culture positive for IE, evidence of endocardial involvement, echocardiogram positive for IE, and new valvular regurgitation. According to the clinical, echocardiographic and biological findings, as well as the results of serologies, the patient did not meet the modified Duke's criteria for diagnosis of endocarditis when he was transferred to our hospital. However, two of the major Duke criteria were met after 
Table 1 Summarizing previously reported cases of C. striatum endocarditis

\begin{tabular}{|c|c|c|c|c|c|c|}
\hline Reference & Age & Sex & Associated illness & Valve & Intervention & Outcome \\
\hline 8 & 76 & $M$ & None & Aortic & Medical & Died \\
\hline 7 & 54 & M & Hypertension & Aortic & Medical and surgical & Survived \\
\hline 9 & 73 & M & Pacemaker & Tricuspid & Medical and surgical & Survived \\
\hline 10 & 24 & M & Ventricular shunt & Pulmonary & Medical & Survived \\
\hline 11 & 68 & M & Hypertension & Mitral & Medical & Survived \\
\hline 12 & 72 & $\mathrm{~F}$ & Prosthetic valve & Aortic & Medical & Died \\
\hline 13 & 62 & $\mathrm{~F}$ & Prosthetic valve & Aortic & Medical & Survived \\
\hline 14 & 50 & M & Mycotic aneurysm & Aortic & Medical and surgical & Survived \\
\hline 15 & 61 & $\mathrm{~F}$ & Rheumatic fever & Mitral & Medical & Survived \\
\hline 15 & 72 & $\mathrm{~F}$ & Prosthetic valve & Mitral & Medical & Survived \\
\hline 16 & 46 & $\mathrm{~F}$ & Hemodialysis & Tricuspid & Medical & Survived \\
\hline 17 & 68 & M & Prosthetic valve & Mitral & Medical & Survived \\
\hline 18 & 69 & $\mathrm{~F}$ & Endometrial cancer & Mitral & Medical and surgical & Survived \\
\hline 19 & 77 & $\mathrm{~F}$ & None & Mitral & Medical & Survived \\
\hline 6 & 62 & M & Hypertension & Aortic & Medical and surgical & Survived \\
\hline 20 & 73 & $\mathrm{~F}$ & $\begin{array}{l}\text { Hypertension, chronic kidney disease, } \\
\text { and diabetes mellitus }\end{array}$ & Mitral & Medical & Survived \\
\hline 21 & 83 & M & Metastatic prostate cancer & Mitral & Medical & Died \\
\hline 22 & 71 & M & Diabetes mellitus & Mitral & Medical and surgical & Died \\
\hline 23 & 71 & $\mathrm{~F}$ & $\begin{array}{l}\text { Pacemaker } \\
\text { prosthetic valve }\end{array}$ & Mitral & Medical and surgical & Survived \\
\hline 24 & 62 & M & $\begin{array}{l}\text { Cardiomyopathy, diabetes mellitus } \\
\text { and osteomyelitis }\end{array}$ & Aortic & Medical and surgical & Survived \\
\hline 25 & 69 & $\mathrm{~F}$ & ANCA+ vasculitis & Mitral & Medical and surgical & Died \\
\hline 26 & 51 & M & Pacemaker & Not described & Medical and surgical & Survived \\
\hline 27 & 56 & M & $\begin{array}{l}\text { Diabetes mellitus, chronic kidney disease, } \\
\text { and osteomyelitis }\end{array}$ & Mitral & Medical and surgical & Died \\
\hline 28 & 78 & M & $\begin{array}{l}\text { Chronic kidney disease, diabetes mellitus } \\
\text { and pacemaker }\end{array}$ & Tricuspid and right ventricular wall & Medical and surgical & Survived \\
\hline 29 & 53 & $\mathrm{~F}$ & None & Quadricuspid aortic & Medical and surgical & Survived \\
\hline
\end{tabular}

the first operation-the positive blood culture and echocardiographic findings-enabling a definitive diagnosis [31]. Looking back, Corynebacterium was present in the first surgical specimen in our case. Therefore, the left atrial mass should have been considered an occult bacterial vegetation. The C. striatum was likely completely surrounded by fibrous tissue, so the patient had no signs of infection until bacteria were released by the first surgery. Ori Elkayam et al. [22] pointed out that IE is the most common manifestation of C. striatum, particularly in patients with nosocomial risk factors. But it is a potential pathogen even in normal hosts with no risk factors, such as our patient. Therefore, in addition to the routine pathological examination, special stains such as Gram staining or Wright's staining should be performed if a few macrophages are seen. When a patient with suspected myxoma develops an unmanageable fever postoperatively, physicians should be alert to the progress of IE and evaluate the possibility with a combined pathological examination and blood cultures. The pathological examination of resected tissue or embolic fragments remains the gold standard for the diagnosis of IE. Nevertheless, we fell into a trap in this case because no pathogens were found in the first or second surgical specimens on examination with a medical microscope at a $400 \times$ magnification (Fig. 2f). We confirmed that C. striatum in positive blood cultures was responsible for the IE and that this diagnosis was supported by the results of Gram staining and Wright's staining of tissue specimens viewed at a 1000x magnification with an oil immersion lens. Daptomycin is an effective drug for $C$. striatum and has been used in some patients with endocarditis caused by this organism [28]. Combined antibiotic treatment and surgery were performed because of the uncontrolled infection and severe aortic regurgitation based on the ESC guidelines [32]. The patient had a slow, uneventful recovery. 


\section{Conclusions}

Corynebacterium in positive blood cultures cannot simply be assumed to be a contaminant. The diagnosis of IE should be suspected, particularly in high-risk patients or those with an unexplained fever. Gram staining can provide additional support for a diagnosis of IE, particularly when the pathological examination implies an inflammatory response, and we should consider the size of the pathogenic bacteria and select the appropriate magnification when examining slides. This can guide postoperative antibiotic use and reduce the risk of a second surgery. In addition, it is necessary to make a suitable standard analysis protocol of cardiac masses to include thorough microbiological analysis, which can reduce misdiagnosis and improve the standard of care.

\section{Additional file}

Additional file 1: Video that demonstrates a $2.7 \mathrm{~cm}$ left atrial mass attached by a thin stalk to the base of the atrial apex, which was extremely similar to the myxoma, freely swing within the left atrial cavity, $7 \mathrm{~s}, 6.8 \mathrm{MB}$. (MP4 $6644 \mathrm{~kb})$

\section{Abbreviations}

C. striatum: Corynebacterium striatum; CT: Computed tomography; hsCRP: Hypersensitive C-reactive protein; IE: Infective endocarditis;

TEE: Transesophageal echocardiography; TTE: Transthoracic echocardiography; WBC: White blood cell counts

\section{Acknowledgements}

None.

\section{Funding}

Not applicable.

\section{Availability of data and materials}

All data contained within the manuscript.

\section{Authors' contributions}

Jun Xu was responsible for the acquisition of data and drafted the manuscript; Xia Zheng revised it critically for important intellectual content and gave final approval to the version to be published. Qing Yang and Jun Li were responsible for Lab test and histologic examination. All authors read and approved the final manuscript.

\section{Competing interests}

The authors declare that they have no competing interests.

\section{Consent for publication}

Written informed consent was obtained from the patient for publication of this case report and the accompanying images.

Ethics approval and consent to participate Not applicable.

\section{Publisher's Note}

Springer Nature remains neutral with regard to jurisdictional claims in published maps and institutional affiliations.

\section{Author details}

${ }^{1}$ Intensive Care Unit, The First Affiliated Hospital, College of Medicine, Zhejiang University, 79 Qingchun Road, Hangzhou 310003, People's Republic of China. ${ }^{2}$ Department of Clinical Laboratory, The First Affiliated Hospital, College of Medicine, Zhejiang University, Hangzhou, People's Republic of
China. ${ }^{3}$ Department of Pathology, The First Affiliated Hospital, College of Medicine, Zhejiang University, Hangzhou, People's Republic of China.

Received: 1 October 2016 Accepted: 16 May 2017

Published online: 26 May 2017

\section{References}

1. Duval X, Delahaye F, Alla F, et al. Temporal trends in infective endocarditis in the context of prophylaxis guideline modifications: three successive population-based surveys. J Am Coll Cardiol. 2012;59(22):1968-76. doi:10. 1016/j.jacc.2012.02.029

2. Thuny F, Di Salvo G, Disalvo G, et al. Risk of embolism and death in infective endocarditis: prognostic value of echocardiography: a prospective multicenter study. Circulation. 2005;112(1):69-75. doi:10.1161/ CIRCULATIONAHA.104.493155.

3. Pérez de Isla L, Zamorano J, Lennie V, Vázquez J, Ribera JM, Macaya C. Negative blood culture infective endocarditis in the elderly: long-term follow-up. Gerontology. 2007;53(5):245-9. doi:10.1159/000101691.

4. Muñoz P, Kestler M, De Alarcon A, et al. Current epidemiology and outcome of infective Endocarditis: a multicenter, prospective, cohort study. Medicine (Baltimore). 2015;94(43):e1816. doi:10.1097/MD.0000000000001816.

5. Severo CB, Guazzelli LS, Barra MB, Hochhegger B, Severo LC. Multiple pulmonary nodules caused by Corynebacterium Striatum in an immunocompetent patient. Rev Inst Med Trop Sao Paulo. 2014;56(1):89-91. doi:10.1590/S0036-46652014000100015.

6. Belmares J, Detterline S, Pak JB, Parada JP. Corynebacterium endocarditis species-specific risk factors and outcomes. BMC Infect Dis. 2007;7(1):4. doi: 10.1186/1471-2334-7-4

7. Rufael DW, Cohn SE. Native valve endocarditis due to Corynebacterium Striatum: case report and review. Clin Infect Dis. 1994;19(6):1054-61. doi:10. 1093/clinids/19.6.1054

8. Markowitz SM, Coudron PE. Native valve endocarditis caused by an organism resembling Corynebacterium Striatum. J Clin Microbiol. 1990;28(1):8-10.

9. Melero-Bascones M, Muñoz P, Rodríguez-Créixems M, Bouza E. Corynebacterium Striatum: an undescribed agent of pacemaker-related endocarditis. Clin Infect Dis. 1996;22(3):576-7. doi:10.1093/clinids/22.3.576.

10. Tattevin P, Cremieux AC, Muller-Serieys C, Carbon C. Native valve endocarditis due to Corynebacterium Striatum: first reported case of medical treatment alone. Clin Infect Dis. 1996;23(6):1330-1. doi:10.1093/ clinids/23.6.1330.

11. Juurlink DN, Borczyk A, Simor AE. Native valve endocarditis due to Corynebacterium Striatum. Eur J Clin Microbiol Infect Dis. 1996;15(12):963-5

12. de Arriba JJ, Blanch JJ, Mateos F, Martínez-Alfaro E, Solera J. Corynebacterium Striatum first reported case of prosthetic valve endocarditis. J Inf Secur. 2002;44(3):193. doi:10.1053/jinf.2001.0927.

13. Houghton T, Kaye GC, Meigh RE. An unusual case of infective endocarditis. Postgrad Med J. 2002;78(919):290-1. doi:10.1136/pmj.78.919.290.

14. Kocazeybek B, Ozder A, Kucukoglu S, Kucukates E, Yuksel H, Olga R. Report of a case with polymicrobial endocarditis related to multiresistant strains. Chemotherapy. 2002:48(6):316-9.

15. Stoddart B, Sandoe JAT, Denton M. Corynebacterium Striatum endocarditis masquerading as connective tissue disorders. Rheumatology (Oxford). 2005: 44(4):557-8. doi:10.1093/rheumatology/keh519.

16. Shah M, Murillo JL. Successful treatment of Corynebacterium Striatum endocarditis with daptomycin plus rifampin. Ann Pharmacother. 2005 39(10):1741-4. doi:10.1345/aph.1G242

17. Mashavi M, Soifer E, Harpaz D, Beigel Y. First report of prosthetic mitral valve endocarditis due to Corynebacterium Striatum: successful medical treatment. Case report and literature review. J Inf Secur. 2006:52(5):e139-41. doi:10.1016/j.jinf.2005.08.027

18. Tibrewala AV, Woods CJ, Pyrgos VJ, Ruiz ME. Native valve endocarditis caused by C. striatum. Scand J Infect Dis. 2006;38(9):805-7. doi:10.1080/ 00365540600606598

19. Elshibly S, Xu J, Millar BC, Armstrong C, Moore JE. Molecular diagnosis of native mitral valve endocarditis due to Corynebacterium Striatum. $\mathrm{Br} J$ Biomed Sci. 2006:63(4):181-4.

20. Marull J, Casares PA. Nosocomial valve endocarditis due to corynebacterium striatum: a case report. Cases J. 2008;1(1):388. doi:10.1186/1757-1626-1-388.

21. Bhat $Y$, Bal AM, Rochow S, Gould IM. An unusual case of Corynebacterium Striatum endocarditis and a review of the literature. Int J Infect Dis. 2008: 12(6):672-4. doi:10.1016/j.jijid.2007.12.010. 
22. Boltin D, Katzir M, Bugoslavsky V, et al. Corynebacterium Striatum-a classic pathogen eluding diagnosis. Eur J Intern Med. 2009;20(3):e49-52. doi:10. 1016/j.ejim.2008.08.009.

23. Oliva A, Belvisi V, lannetta M, et al. Pacemaker lead endocarditis due to multidrug-resistant Corynebacterium Striatum detected with sonication of the device. J Clin Microbiol. 2010;48(12):4669-71. doi:10.1128/JCM.01532-10.

24. Batalla $A S$, de La Blanchardière $A$, Vergnaud $M$, Dargère $S$, Verdon $R$. Recurrent Corynebacterium Striatum endocarditis, secondary to osteomyelitis. Med Mal Infect. 2011;41(3):160-3. doi:10.1016/j.medmal. 2010.11.004

25. Deligeoroglou E, Fotaki P, Kokkalis D, Creatsas G. Description of 8 cases with gonadal dysgenesis syndrome type 46XY. Akush Ginekol (Sofiia). 2001;42(2): 9-12. doi:10.3201/eid0801.010151.

26. Knox KL, Holmes AH. Nosocomial endocarditis caused by Corynebacterium amycolatum and other nondiphtheriae corynebacteria. Emerging Infect Dis. 2002;8(1):97-9. doi:10.3201/eid0801.010151.

27. Tran $\pi$, Jaijakul $\mathrm{S}$, Lewis $C T$, et al. Native valve endocarditis caused by Corynebacterium Striatum with heterogeneous high-level daptomycin resistance: collateral damage from daptomycin therapy? Antimicrob Agents Chemother. 2012;56(6):3461-4. doi:10.1128/AAC.00046-12.

28. Fernández Guerrero ML, Molins A, Rey M, Romero J, Gadea I. Multidrugresistant Corynebacterium Striatum endocarditis successfully treated with daptomycin. Int J Antimicrob Agents. 2012;40(4):373-4. doi:10.1016/j. ijantimicag.2012.06.001.

29. Fernández Guerrero ML, Robles I, Nogales MDC, Nuevo D. Corynebacterium Striatum: an emerging nosocomial drug-resistant endocardial pathogen. J Heart Valve Dis. 2013;22(3):428-30.

30. Mizoguchi H, Sakaki M, Inoue K, et al. Quadricuspid aortic valve complicated with infective endocarditis: report of a case. Surg Today. 2014;44(12):238891. doi:10.1007/s00595-014-0844-1.

31. Li JS, Sexton DJ, Mick N, et al. Proposed modifications to the Duke criteria for the diagnosis of infective endocarditis. Clin Infect Dis. 2000;30(4):633-8. doi:10.1086/313753.

32. Habib G, Lancellotti P, Antunes MJ, et al. 2015 ESC guidelines for the Management of Infective Endocarditis: the task force for the management of infective Endocarditis of the European Society of Cardiology (ESC). Endorsed by: European Association for Cardio-Thoracic Surgery (EACTS), the European Association of Nuclear Medicine (EANM). Eur Heart J. 2015;36(44): 3075-128. doi:10.1093/eurheartj/ehv319.

\section{Submit your next manuscript to BioMed Central and we will help you at every step:}

- We accept pre-submission inquiries

- Our selector tool helps you to find the most relevant journal

- We provide round the clock customer support

- Convenient online submission

- Thorough peer review

- Inclusion in PubMed and all major indexing services

- Maximum visibility for your research

Submit your manuscript at wuw biomedcentral.com/submit

) Biomed Central 